\title{
The Emotion and Imagery Characterizing the Vocabularies of Special Englishes Designed for Later Language Learners
}

\author{
Cynthia Whissell \\ Psychology Department, Laurentian University, Sudbury, Ontario, Canada
}

\section{Email address:}

cwhissell@laurentian.ca

\section{To cite this article:}

Cynthia Whissell. The Emotion and Imagery Characterizing the Vocabularies of Special Englishes Designed for Later Language Learners. International Journal of Language and Linguistics. Vol. 3, No. 6, 2015, pp. 372-376. doi: 10.11648/j.ij11.20150306.19

\begin{abstract}
Two Special Englishes designed for later language learners - Ogden's Basic English and the Voice of America's Simple English - propose the use of a limited English vocabulary. The emotional associations, abstraction, length, and frequency of vocabulary words in these two systems were studied in comparison to Everyday English. Not surprisingly, the limited vocabularies of the two Special Englishes contained shorter and more common words than Everyday English. The Special Englishes were both more pleasant in their associations than Everyday English and more concrete (less abstract). Simple English was more active and arousing in its associations while Basic English was less so. It is suggested that teachers of later learners should be aware of the ways in which limited vocabularies skew the emotional connotations of texts and differentiate experiences of later language learners from those of more experienced users.
\end{abstract}

Keywords: Later Language Learners, English, Emotion

\section{Introduction}

\subsection{Aim of the Paper}

This paper examines the emotional associations and imagery of words in the vocabularies of two Special Englishes that were designed for later language learners - Basic and Simple English - and reasons that emotion and imagery colour the languages and differentiate them from Everyday English.

\subsection{The Importance of a Lingua Franca}

Since the beginning of the $20^{\text {th }}$ century a veritable barrage of new languages has been created in efforts to improve communication among peoples; examples include Esperanto, Volapük. Novial, and Lojban (Lo Bianco, 2004). These languages were designed to promote direct and effective interchanges among speakers of different original languages, and to be relatively free of value systems because they were not entirely embedded within a single culture. In actual fact, the global lingua franca (or, more accurately, lingua anglica) of today is not a value- and culture-free language but rather one associated with two of the most widely influential and dominant cultures of recent history - Great Britain and the United States (Crystal, 2003, chapter 2). It has been suggested that the teaching of a dominant language such as English to indigenous communities around the world may have the effect of linguistically colonizing the communities and of "othering" their native languages (e.g., Iseke-Barnes, 2004). On the other hand, given that a lingua franca is needed for communication among cultures (Crystal, 2003, chapter 1; Templer, 2006), some languages are likely to serve better in the role than others because of their history. This paper does not address the issue of language colonization but focuses rather on the words employed in systems designed to teach English effectively to later learners as an additional, not a replacement, language.

\section{English for Later Learners}

\subsection{Special Englishes}

There are many different forms of English with distinctions existing even between neighboring forms such as US and Canadian English and certainly between Asian and European Englishes that are separated by both distance and culture. Two Special Englishes or forms of English designed for communication among speakers of other languages are Ogden's Basic English ${ }^{1}$ and Simple English ${ }^{2}$ from the Voice

$1 \mathrm{http}: / /$ ogden.basic-english.org/basiceng.html

2 http://www.simplish.org/learn-basic-english/VOA/ 
of America. These were fashioned and promoted during the first and second halves of the $20^{\text {th }}$ century respectively, and they fall into Lo Bianco's (2004, p. 13) category of modified languages or Kuhn's (2014) class of controlled natural languages because they are delimited forms of an existing language. Both Englishes are of interest to $21^{\text {st }}$ century teachers of English (Templer, 2006), and both have a presence on the internet. ${ }^{3}$ There is a Wikipedia page written largely in Basic English, ${ }^{4}$ and Kuhn (2014) describes Basic English as the longest lasting controlled natural form of English. The Voice of America currently provides news reports in variously graded forms of English.

Each of the Special Englishes consists of a subset of English words ( 850 for Basic and 1500 for Simple) with a potential for expansion. The stated aim of both Special Englishes is simplicity in aid of clearer communication. This simplicity is evident in the selection of shorter and more common words for inclusion in the basic list. The vocabularies of both languages are a subset of English designed to represent its meanings as fully as possible. Both vocabularies were created by selecting what were considered key words from a broader English vocabulary. Basic English has one additional characteristic: it employs very few verbs because Ogden believed that a multitude of verbs does not promote clear communication. ${ }^{5}$ For example, do we need different words to express the meanings of "give" and "bestow" or the meanings of "go" and "proceed"? In each case the first verb is in Basic while the second is not. The verbs in Basic English are limited to ones such as "come," "have," and "see."

\subsection{Examples of Special English Texts}

Several documents (including the Christian Bible) have been translated (rendered into Basic) by proponents of Basic English. Below, for example, is an excerpt from the introductory paragraphs of Edgar Allan Poe's 1843 short story The Gold Bug, first in its original form and then in Basic English. Differences in vocabulary (e.g., "meeting" for "acquaintance" and "sad" for "melancholy") are immediately obvious. Sentence structures have also been changed and the order of presentation of information has been modified (e.g., in the first sentence). Some of the original flavour of Poe's writing is missing in the translation, but the translation is considerably easier for a later language learner to read. The readability statistics provided by

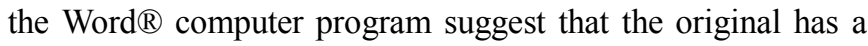
Reading Ease of $49.4 \%$ and a Grade Level of 12.9 (equivalent to first year university) while the Basic translation has a Reading Ease of $72.4 \%$ and a Grade Level of 8.8 (typical of North American students who are 12-13 years old).

In the inmost recesses of this coppice, not far from the eastern or more remote end of the island, Legrand had built himself a small hut, which he occupied when I first, by mere accident, made his acquaintance. This soon ripened into

\footnotetext{
$3 \mathrm{http}: / /$ learningenglish.voanews.com/ http://basic-english.org/

$4 \mathrm{https} / / /$ simple.wikipedia.org/wiki/Main_Page

5 http://ogden.basic-english.org/isl121.html
}

friendship - for there was much in the recluse to excite interest and esteem. I found him well educated, with unusual powers of mind, but infected with misanthropy, and subject to perverse moods of alternate enthusiasm and melancholy. ${ }^{6}$

Legrand had made himself a small house in the thickest part of this undergrowth, near the east, or far end of the island, and he was living there when by chance we had our first meeting. In a short time he became my friend, for he was the sort of man for whom one's interest quickly becomes respect, though he had no taste for company. It was clear that he had been given a good education and had uncommon powers of mind; but he was troubled by a feeling that men were against him and by strange humours; one minute he would be completely happy and a minute later deeply sad -- all for no reason. ${ }^{7}$

The Voice of America does not offer translations but rather short forms of some of Poe's works. Below are the opening sentences of Poe's 1845 short story The Purloined Letter in its original form and the opening sentences of a Voice of America synopsis. Differences in vocabulary (the words "meditation" and "meerschaum" do not appear in the synopsis at all) and in sentence structure (Poe's first sentence is 49 words long, but the first sentence of the synopsis is only 18 words long) are easily noted. The Poe original has a Readability Ease of $44.7 \%$ and a Grade Equivalent of 14 (second year university). The synopsis has a Readability Ease of $69.4 \%$ and a Grade Level of 7.3 (equivalent to ages 10-11).

At Paris, just after dark one gusty evening in the autumn of 18--, I was enjoying the twofold luxury of meditation and a meerschaum, in company with my friend C. Auguste Dupin, in his little back library, or book-closet, au troisieme, No. 33, Rue Dunot, Faubourg St. Germain. For one hour at least we had maintained a profound silence; while each, to any casual observer, might have seemed intently and exclusively occupied with the curling eddies of smoke that oppressed the atmosphere of the chamber. $^{8}$

One evening in Paris, during the autumn of eighteen forty-five, I went to visit a friend, Auguste Dupin. We were smoking our pipes and talking when the door of his apartment opened. Mr. Germont, the head of the Paris police force, came into the room. ${ }^{9}$

\subsection{The Connotative Meanings of Words}

The meanings of individual words may seem obvious because words can be defined in terms of dictionaries and usages, but some parts of meaning are hidden (connotative) rather than obvious and these were not involved in the selection of the vocabularies. Words convey information in more than one way. They denote or point to something in particular (the word "party" denotes a celebratory gathering) and they also carry an additional layer of hidden or

\footnotetext{
6 http://xroads.virginia.edu/ hyper/http://xroaPOE/gold_bug.html

$7 \mathrm{http}$ ://ogden.basic-english.org/books/goldinsect.html\#text

$8 \mathrm{http}: / /$ xroads.virginia.edu/ hyper/POE/purloine.html

9http://www.21 voa.com/VOA_Special_English/purloined-letter-edgar-allan-poe-a merican-stories-11050.html
} 
connotative meaning ("party" implies happiness and excitement; Whissell, 2009). This paper examines the connotative meanings of Basic and Simple English by looking at the vocabulary of each and scoring words in terms of the Dictionary of Affect, a tool designed to assess connotative meaning in terms of three dimensions (Whissell, 2009). The Dictionary is composed of people's ratings of the connotations of words in terms of Pleasantness (How Pleasant is this word?) Activation (How Aroused or Active is this word?) and Imagery (How easy is it to form a mental picture of this word?). The first two are recognized dimensions of emotion (Osgood, 1969; Russell, 1978), and the third is a measure of language abstraction important to the way in which the mind operates (Paivio, 2007, p. 8). Words that are easily mentally envisioned (e.g. "tree") are concrete, while those that are difficult to picture (e.g., "justice") are abstract. The rating scales employed in gathering Dictionary data ranged from 1 to 3. In terms of its connotations, "party" is close to the high end of the scale and therefore pleasant (2.50), active (2.75) and concrete or easy to picture (2.60). The numbers associated with single words such as "party" represent the average of the ratings assigned to the word by many participants.

\subsection{Comparisons to Everyday English}

In this research, the Dictionary of Affect itself represents the Englishes of the North American continent. The Dictionary's word list was created in an ecologically valid manner (Whissell, 2009): words were taken from many different samples of Everyday sources such as newspaper texts, books, television shows and essays: they represent the English that a North American would hear or read on an everyday basis. The Dictionary contains 8735 English words so that it, also, is a subset of English as a whole which contains tens of thousands of words.

The three Englishes represented here - Basic, Simple, and Everyday (Dictionary of Affect), were compared to one another in order to establish the connotative character of the Special Englishes. At the most general level, it is suggested that creating a form of English with a limited vocabulary for later language learners might have the effect of skewing or misrepresenting the connotations of the language as a whole. Such a skew could have both positive and negative outcomes. For example, if words in the Special Englishes are much more concrete than those in Everyday English, then the abstraction of English is being misrepresented by the lists. At the same time, learners are being encouraged to focus on words that might be easier to learn and use because of their associated imagery.

\section{Method}

\subsection{Data Collection and Analysis}

Word lists for Basic ${ }^{10}$ and Simple ${ }^{11}$ English were

10 http://ogden.basic-english.org/wordalph.html, May 2015

11 www.lib.intuit.kg (Google Cache), May, 2015 downloaded from the internet. Words repeated within the Simple English list because of multiple meanings or senses were reduced to a single word in order to maintain parallelism between lists. Words for each list were then matched to the Dictionary and scored in terms of their Pleasantness, Activation, and Imagery. Only words with an exact Dictionary match were scored; there was a $92 \%$ match rate for Basic and a $90 \%$ match rate for Simple English. Words not matched by the Dictionary (e.g., bucket, apparatus, anarchy) were those not used at a high rate in the Everyday English characterizing the Dictionary. Only $63 \%$ of the words in the Basic list were also in the Special English list. Historical changes and cultural differences likely account for many of the disagreements between lists. Word length and word frequency were also compared across lists. Word length was scored in terms of number of letters and word frequency was estimated by comparison to a broadly sampled corpus of approximately 348 thousand words (Whissell, 1998).

\subsection{Subtypes of Basic English Words}

Words in Basic English are divided into five key categories - Operations (this category contains contain verbs such as "go" and "have"), Things (nouns such as "polish," "manager," and "year"), Picturable Things (high imagery nouns such as "knee," "stick," and "worm"), Qualities (adjectives such as "beautiful," "military," and "wise") and Opposite Qualities (adjectives with mostly negative connotations such as "cold," "dead," "thin," and "wrong"). Means for Pleasantness, Activation, and Imagery were obtained for words in each category.

Table 1. Differences among Vocabularies.

\begin{tabular}{lllll}
\hline Variable & Basic & Simple & Everyday & p \\
\hline Length & $5.25^{\mathrm{a}}$ & $5.56^{\mathrm{b}}$ & $7.06^{\mathrm{c}}$ & $<.001$ \\
Frequency & $185.54^{\mathrm{a}}$ & $156.93^{\mathrm{a}}$ & $39.23^{\mathrm{b}}$ & $<.001$ \\
Pleasantness & $1.89^{\mathrm{a}}$ & $1.88^{\mathrm{a}}$ & $1.84^{\mathrm{b}}$ & .001 \\
Activation & $1.79^{\mathrm{a}}$ & $1.86^{\mathrm{b}}$ & $1.85^{\mathrm{b}}$ & .002 \\
Imagery & $2.22^{\mathrm{a}}$ & $2.09^{\mathrm{a}}$ & $1.93^{\mathrm{b}}$ & .017 \\
\hline
\end{tabular}

a, b, c Any two means in the same row with a different superscript are significantly different from one another according to two-tailed $t$ tests $(p<.05)$.

\section{Results}

\subsection{Statistical Analyses}

One-way analyses of variance and post hoc $t$ tests were employed to compare the three lists. There were significant differences among lists in terms of all measures - word frequency, length, Pleasantness, Activation, and Imagery (Table 1).

\subsection{Simplicity of Special English Vocabularies}

The simplicity of the Special English vocabularies is evident in their inclusion of shorter and more common words than Everyday English (Table 1). Although words from Basic are significantly shorter than those from Simple English, both of these are shorter than Everyday words by roughly a letter and a half. Word frequency is similar for the two Special Englishes (185 and 157 mentions per 348 thousand words), 
and significantly higher than that for Everyday English (39 mentions). These results were expected because they reflect the philosophy of simplicity underlying the Special Englishes.

\subsection{Connotations of Special English Vocabularies}

Both Special English vocabularies included more highly Imaged words than did Everyday English. The words chosen for inclusion in Basic and Simple English were those that are easily pictured - they are concrete rather than abstract.

Both Special Englishes had a more Pleasant vocabulary than Everyday English. This means that a learner focusing on the limited vocabularies of these Special Englishes would be learning a vocabulary whose associations were more Pleasant than those encountered in Everyday English.

Simple English from the Voice of America had a vocabulary with more Active words than Everyday English. Basic English, on the other hand, had a vocabulary with less Active (more Passive) words than Everyday English. The difference between the Special Englishes was almost certainly affected by Ogden's stated distrust of verbs and his limitation of the number of verbs in the Basic vocabulary. The fact that Basic English is older and British rather than American may also have contributed to this result.

Table 2. Differences among Types of Basic Words.

\begin{tabular}{llll}
\hline Type of Word Pleasantness & Activation & Imagery & \\
\hline Operations & $1.78^{\mathrm{c}, \mathrm{d}}$ & $1.61^{\mathrm{c}}$ & $1.40^{\mathrm{e}}$ \\
Things & $1.93^{\mathrm{a}}$ & $1.88^{\mathrm{a}}$ & $2.24^{\mathrm{b}}$ \\
Picturable Things & $1.85^{\mathrm{a}, \mathrm{d}}$ & $1.69^{\mathrm{b}}$ & $2.85^{\mathrm{a}}$ \\
Qualities & $1.96^{\mathrm{a}}$ & $1.82^{\mathrm{a}}$ & $1.95^{\mathrm{d}}$ \\
Opposite Qualities & $1.69^{\mathrm{c}}$ & $1.67^{\mathrm{b}, \mathrm{c}}$ & $2.12^{\mathrm{c}}$ \\
\hline
\end{tabular}

a, b, c, d Any two means within the same column with a different superscript are significantly different from one another (two-tailed $t$ tests, $p<.05$ ).

\subsection{Comparisons Among Types of Basic Words}

Table 2 describes differences among the five different types of Basic words outlined in the Method section. Ogden's common English verbs had a very definite connotative character: Operations were notably less Pleasant, less Active, and less Imaged than other types of Basic words. This finding supports the conclusion that the low Activation ratings of Basic English were partly due to its verbs. However, it should be noted that of the five categories of words, only Things matched or exceeded Everyday English in terms of Activation. Qualities were more Pleasant and Active then Opposite Qualities, but they were also more abstract (they had a lower Imagery). Things, and especially Picturable Things, were highly imaged.

\section{Conclusions}

\subsection{Overview}

The Special Englishes studied in this paper had limited vocabularies. Their words were more commonly used, more concrete and shorter than those in Everyday English. This simplicity and reduced abstraction accords with the aim of the developers of each vocabulary. The vocabularies, however, also differed from Everyday English in terms of their connotative or less obvious meanings. Words in both lists conveyed more pleasant associations than those in Everyday English. With respect to activation, Simple English packed a punch because its words were unusually active while Basic English provided a quieter, more passive picture of the language. Teachers of English for later learners would do well to examine the connotations as well as the simplicity of their chosen vocabularies. If the trends observed here were generalized to other forms of English in use, one could infer that the more complex and larger a vocabulary grew, the more likely it would be that its words would be rarer, longer, more abstract, and more emotionally flat or even-toned.

It could be argued that later language learners would not be sensitive to the skewed connotations of the limited vocabularies because they do not have a standard for comparison (the ratings employed, after all, come from speakers of Everyday English). However, teachers of English, whether they are consciously aware of the differences or not, are likely to perpetuate them. As well, a later language learner developing his or her language skills to a higher level might notice the difference. By making English simple, Ogden and the Voice of America have also made it sweeter and more concrete. Moreover, differences between the two Special Englishes suggest that selected vocabularies can differ from one another as well as differing from everyday English.

\subsection{Emotion as a Necessary Consideration}

In comparing various controlled natural languages, Kuhn (2014) employed the criteria of precision (exactitude), expressiveness (of denotative meaning), naturalness (where speakers of the original language would not find the controlled language bizarre), and simplicity (in comparison to the original language). As Kuhn was evaluating the logical expressiveness of controlled languages, he did not mention the importance of emotional connotations, although it could be argued that emotional connotations are subsumed under expressiveness. If the aim of a controlled language is "to improve communication among humans" (Kuhn, 2014, p. 121), then perhaps affective expressiveness should be added to the other four criteria. Kuhn's PENS system (Precision, Expressiveness, Naturalness, Simplicity) would then become PENSA (Precision, Expressiveness, Naturalness, Simplicity, Affectivity). The addition of affectivity chimes well with concerns discussed in the current literature addressing the acquisition of additional languages. The importance of word emotionality for later language learners has been noted by Caldwell-Harris in terms of decision making (2012) and in terms of bridging the cognition-emotion divide (2014). As well, Ferré. Ventura, Comesaña and Fraga (2015) have demonstrated that emotional and concrete words are the easiest for second-language learners to master. These researchers worked with relatively limited sets of words. Instruments such as the Dictionary of Affect in Language allow for the evaluation of word emotionality in much larger 
samples.

Rowse (2011) humorously proposed that the "new world lingo" should be Amglish (a texting-and-slang-based form of English) rather than some other carefully controlled form of the language. He defines Amglish as "informal American English, the first truly international tongue, the lingua franca for communicating between countries with native languages other than English" and notes that it borrows freely from other world languages (p. 5). Given that it evolved from mass communication media such as texting, one could pretty well guarantee that Amglish would be affectively expressive, especially if it includes emojis!

\section{References}

[1] Caldwell-Harris, Catherine. "How knowing a foreign language can improve your decisions." Scientific American, 2012, http://www.scientificamerican.com/article/foreign-language-i mprove-decisions/.

[2] Caldwell-Harris, Catherine. "Emotionality differences between a native and foreign language: theoretical implications." Frontiers in Psychology, 2015, Article 1055.

[3] Crystal, David. English as a Global Language, $2^{\text {nd }}$ edition. Cambridge, UK, Cambridge University Press, 2003.

[4] Ferré, Pilar, Ventura, David, Comesaña, Montserrat, \& Fraga, Isabel. "The role of emotionality in the acquisition of new concrete and abstract words." Frontiers in Psychology, 2015, Article 976.
[5] Iseke-Barnes, Judy M. "Politics and power of languages: indigenous resistance to colonizing experiences of language dominance." Journal of Thought, 2004, 39, 45-81.

[6] Kuhn, Tobias. "A survey and classification of controlled natural languages.” Computational Linguistics, 2014, 40, 121-170.

[7] Lo Bianco, Joseph. "Invented languages and new worlds." English Today, 2004, 20, 8-18.

[8] Osgood, Charles E. "On the whys and wherefores of E, P, and A." Journal of Personality and Social Psychology, 1969, 12, 194-199.

[9] Paivio, Allan. Mind and its Evolution: a Dual Coding Theoretical Approach. Mahwah, New Jersey, Erlbaum, 2007.

[10] Rowse, Arthur E. Amglish, in like, ten easy lessons: a celebration of the new world lingo. Maryland, Rowman \& Littlefield, 2011.

[11] Russell, James A. "Evidence of convergent validity on the dimensions of affect." Journal of Personality and Social Psychology, 1978, 36, 1152-1168.

[12] Templar, Bill. "Revitalizing 'Basic English' in Asia: new directions in English as a lingua franca. TESL Reporter, 2006, $39,17-33$.

[13] Whissell, Cynthia. "A parsimonious technique for the analysis of word-use patterns in English texts and transcripts. Perceptual and Motor Skills, 1998, 86, 595-613.

[14] Whissell, Cynthia. "Using the revised Dictionary of Affect in Language to quantify the emotional undertones in samples of natural language." Psychological Reports, 2009, 105, 509-521. 